\title{
Integrating the Edges: University of Pretoria's Neighbourhood Anchor Strategy
}

Denver Hendricks, Manager of Government Relations and Special Projects, University of Pretoria

Denver.Hendricks@up.ac.za

University of Pretoria

Hatfield 0028

Pretoria, ZA 0002

Jaime Flaherty, Vice President and Chief Financial Officer, U3 Advisors

jflaherty@u3advisors.com

1. U3 Advisors, Inc.

30 South 15th Street

15th Floor

Philadelphia, PA, USA 19102

2156942444

\begin{abstract}
:
The traditionally inward focus of many higher education institutions in both the United States (US) and South Africa has often failed to address important urban issues beyond the university gates, confining most student and academic activity to the campus. Universities can create social change not just through their primary teaching and research functions, but also through the promotion of integration on and around their campuses. In addition, place-based activities that improve neighbourhoods can help to attract students and staff, as well as new businesses and services. In particular, they can foster the influx of young professionals and families seeking to help build open, safe, vibrant and diverse communities, which may represent a new model for South African socioeconomic integration beyond the "gated" framework. Accordingly, the University of Pretoria (UP) has sought to lead an urban renewal and social transformation project around its Hatfield campus.
\end{abstract}

\section{Keywords:}

- anchor strategy

- invest

- real estate

- place based 


\section{Introduction}

In South Africa, universities are seen by many as bastions of exclusivity. Surrounded by high fences, universities are perceived to keep students and academics in, and the rest of the community out. This physical isolation mirrors the social and financial exclusivity that prevents the majority of South Africans from accessing higher education. Despite their different social and political contexts, the challenges facing South Africa's higher education system bear comparison with the struggles around issues of race and class that are continue to unfold on many American campuses. The traditionally inward focus of many higher education institutions in both the United States (US) and South Africa has often failed to address important urban issues beyond the university gates, confining most student and academic activity to the campus.

However, unlike many other areas of life in South Africa that are dominated by racial and economic divisions, universities bring together diverse groups (of students and staff) in pursuit of common goals. In this regard, universities can create social change not just through their primary teaching and research functions, but also through the promotion of integration on and around their campuses (Blaik 2016). In addition, place-based activities that improve neighbourhoods can help to attract students and staff, as well as new businesses and services. In particular, they can foster the influx of young professionals and families seeking to help build open, safe, vibrant and diverse communities, which may represent a new model for South African socio-economic integration beyond the "gated" framework.

Accordingly, the University of Pretoria (UP) has sought to lead an urban renewal and social transformation project around its Hatfield campus. Seeking to leverage its important role as an anchor institution, UP envisions mutual benefits for the surrounding area and itself by aligning key goals. Anchors are often defined as large, permanent institutions (universities, hospitals, and other nonprofit organizations) with stabilizing physical and social ties to their surrounding host communities (Lincoln Institute of Land Policy 2015). Collaborating with local government and community stakeholders, the University of Pretoria has thus developed plans to establish a mixed-use precinct, the Hatfield Campus Village, which can enhance security and a sense of community, as well as fostering local economic growth. The initiative also seeks to address an important long-term goal for UP: enabling the institution to expand in contiguous neighbourhoods while creating safer residential areas for staff and students.

Broadly, the University of Pretoria has adopted a policy of seeking to break down barriers between academia and society, between rich and poor, among racial groups and also among scientific disciplines (University of Pretoria 2016). It views diversity as fundamental to its academic success and capacity to contribute effectively to South Africa's socio-economic development. In order to foster an inclusive cohort, it seeks to enhance student access and pass rates (University of Pretoria 2016). Special emphasis has been placed on supporting students from disadvantaged backgrounds whose inadequate preparation for higher education, among other constraints, creates a barrier to achievement. The university strives to create institutional cultures and practices that support students (and staff) from diverse socio-economic and cultural backgrounds with the goal of eliminating differential success rates based on variables such as race, gender and class. As "an engaged university" (University of Pretoria 2015), UP also recognises the importance and mutual benefit of collaborating with government, industry and community stakeholders to strengthen its responsiveness to, and impact on, socio-economic 
development. It seeks to create physical and intellectual spaces to promote dialogue and the exchange of ideas in pursuit of a more inclusive culture. As part of this strategy of engagement with external actors to promote inclusivity, it is seeking to establish a more accessible, outwardfocused campus. A goal of the envisioned Hatfield Campus Village precinct is to integrate the university more closely into its surrounding community, while enhancing opportunities for student access and academic achievement, as well as work readiness and, ultimately, employment.

Many of the objectives of UP's precinct initiative have been successfully realized by a cohort of urban universities in the United States that have leveraged their institutional demand drivers to revitalize surrounding neighborhoods. Among the most prominent of these universities is the University of Pennsylvania where, between 1997 and 2004, the University administration pioneered what would become known as an "anchor strategy" - so named because of the University's role as an anchor in the surrounding West Philadelphia community (Netter Centre 2008). Such a strategy, while led by the institution, is both community focused and place-based, designed to maximize the anchor institution's impact more positively at the neighbourhood level. Anchor strategies are important because they help attract and retain talent, align with the altruistic fulfillment of an anchor's core mission, provide sustained local economic impacts as opposed to transactional, and potentially enhance financial gain through real estate portfolios and optimized procurement policies.

\section{Anchor Strategies in the US}

Universities are centres of employment, destinations for students, purchasers of goods and services, national centres of research, curators and generators of arts and culture, and owners of real estate, with a key focus on graduates and research. However, they also reside within established residential and commericial neighborhoods that in some cases have historically been overshadowed, ignored, or exploited by the institutions. Over the last two decades, many U.S. anchor institutions and communities have recognized that their health and success are inextricably linked.

The tools that may be tailored to implement anchor strategies vary widely, often depending on the financial capacity, ambitions, size and nature of the institution (e.g, large publicly-endowed universities compared with small private ones), as well as local conditions (e.g. the relative strength or weakness of the housing market and economy). However successful anchor strategies share the general characteristics of being holistic, institutionally embedded, focused around a specific, easily identifiable geographic area, and created in close collaboration with local partners (Lincoln Institute of Land Policy 2015).

The following three projects (University of Pennsylvania, Midtown Detroit, and the University of Maryland) provide an overview of successful, yet diverse approaches to distinct place-based challenges facing three different universities in the US. These examples highlight the major shift in focus that many U.S. institutions have embarked on in the last 10 to 15 years towards selfpreserving efforts to remain competitive and attractive, as well as to serve their host communities. By redeploying their assets and leveraging internal demand, many anchors have successfully transformed their neighborhoods and attracted significant investment. 


\section{University of Pennsylvania, Philadelphia, PA}

In the early 1990s, the area around the University of Pennsylvania's (Penn) campus in West Philadelphia was facing high rates of violent crime, crumbling housing stock, and an exodus of residents. The campus itself was alienated from the surrounding community and Penn struggled to compete for world-caliber faculty and students because of disinvestment in the area. Understanding that the university's academic reputation was inexorably linked to its surroundings, the University's President commissioned a real estate and community development strategy that revolved around the principles of targeted investment, adaptive reuse, and sustained community partnerships. The project, called the West Philadelphia Initiatives, sought to make the neighbourhood secure; create a year-round housing community, with improved job and business opportunities (including new retail, dining and entertainment destinations); foster investment in public education; and, generally, integrate the university into the urban fabric.

The West Philadelphia Initiatives helped to redefine the traditional role of an urban university. Leveraging the diverse resources of the university's academic, financial, and administrative arms, it fostered community alliances to execute a comprehensive neighbourhood and campus revitalisation plan. These efforts created a beneficial interdependency between the institution and community that has strengthened West Philadelphia's long-term economic viability and made it one of the fastest growing neighbourhoods in the city.

The initiatives helped to reduce crime drastically, cleaned up neighbourhood streets, facilitated economic development and job growth, and increased ridership on, and the economic feasibility of, local public transport alternatives (Kromer and Kerman 2004). Institutional investment promoted the development of key parcels along the campus edge into mixed- use projects. The University developed a neighborhood K-8 partnership school with the School District of Philadelphia, which helped attract families to the neighborhood. Housing incentives were offered to faculty and staff and resulted in more than 1,000 home purchases in West Philadelphia, making it one of few communities in Philadelphia to grow during that time. A number of community partnerships were also established including the creation of the University City District (UCD) - a community development organization. UCD manages clean \& safe, marketing, and business attraction programs as well as the West Philadelphia Skills Initiative, which connects local residents to jobs and internships at the neighborhood's anchor institutions.

Penn started the process by investing its own money, thus demonstrating its commitment and encouraging private sector investors to follow. Between 1997 and 2006, Penn was responsible for nearly $\$ 500$ million of real estate development along its campus edge, increasing the university's overall net operating income by $113 \%$ and its retail occupancy from $83 \%$ to $95 \%$. The university's efforts helped to transform the neighbourhood into a vibrant, safe, 24/7 destination for students, faculty, staff, and residents. With a focus on the original core principles, the university created an environment that enhanced diversity, scholarship, arts, and culture. In doing so, they established a new national model for sustainable, university-driven, urban growth. 


\section{Midtown Detroit}

Midtown Detroit adopted a different kind of anchor strategy, based on a unique partnership between civic leaders, philanthropy, anchor institutions, and developers. Surrounded by some of the most devastating urban decline, Midtown Detroit has demonstrated that a comprehensive strategy of place making, sustained over a long period of time, supported by a wide array of stakeholders can turn around the decline and redefine a new chapter in the city that captivated America's imagination for the past century. Together, Detroit's three largest anchors - Detroit Medical Center, Henry Ford Health System (HFHS), and Wayne State University (WSU) employ over 30,000 faculty and staff, enroll over 27,000 students, and spend nearly \$1.6 billion in goods and services annually. Through a data driven approach, a key study concluded that there was tremendous potential to capture the anchors' economic outputs within the City, with less than 10 percent of anchor employees and students living in the area and only 5 percent of goods and services procured within the City of Detroit.

Accordingly, strategic advisors created a place-based economic development strategy that defined Midtown as the urban core of the City. One of the first critical steps was the establishment of Midtown Detroit, Inc. (MDI), a community development corporation that merged two smaller organizations and significantly increased its capacity to deliver clean and safe initiatives, marketing, and programming. Soon after, MDI launched the successful the implementation of a $\$ 1.2$ million housing incentive program known as "Live Midtown." The program provides down- payment assistance, home improvement grants, and rental incentives to employees of the three anchor institutions, and has attracted more than 1,400 new residents to Midtown over the last seven years (Midtown Detroit, Inc. 2017). Based on its success, elements of the programme have been adopted by multiple downtown employers.

A buy local - "Source Detroit" - programme was created to increase institutional purchasing from Detroit-based businesses. Procurement continues to shift to local businesses including \$15 million of new spending by the anchor institutions. In addition, a new knowledge district called TechTown is emerging with the support of Wayne State University, the College of Creative Studies, and the Henry Ford Health System. The district's goal is to lead the city's transition from an automotive to an innovation-based economy. Evidence of the success of the whole strategy and the demonstrative projects have been aplenty, including housing occupancy in the district has been sustained at $96 \%$ over the past few years, over 2,000 new housing units have been built and occupied in the last five years, and approximately 70 new startups established businesses in the district within the last decade.

Over $\$ 3.3$ billion has been invested in development since 2003 and, despite a weak economy and Detroit's egregious fiscal problems, Midtown has been transformed into a desirable destination with improved investment fundamentals and substantial demand for new products. However, the development has required some public-financing support in the form of tax breaks since development costs often greatly exceed market rentable values in such areas. MDI has acted as an intermediary to accelerate development using tax credits and grant funding to supplement traditional financing. For example, the establishment of an Ellington's Whole Foods outlet in the precinct was funded with $\$ 9$ million in equity, \$2.1 million in new market tax credits, \$1 million from the Detroit Economic Growth Corporation, \$1 million from the Michigan Strategic Fund, and $\$ 1.2$ million in brownfield redevelopment tax credits. Midtown Detroit Inc's long-term, 
holistic strategy to "Invest, Capture, Create" has changed the trajectory of this once declining district and forms part of a larger revitalisation strategy for greater downtown Detroit.

\section{University of Maryland, College Park}

The University of Maryland (UMD), the State of Maryland's 38,000 student flagship University, resides 16 kilometers outside of Washington D.C., the U.S capital. Despite the institution's magnitude, education and research prowess, and enthusiastic allegiance from students and alumni, College Park itself was the antithesis of the traditional US college towns where the University's peers are located. Possessing none of the charm, vibrancy, or market demand of a Berkeley, Boulder, or Chapel Hill, the University struggled with competing with their peers for faculty, students, and residents. With a commitment to proactively addressing this challenge, the new president laid out a vision of a Greater College Park where campus and community are seamlessly integrated, where faculty and staff live, work and play in and where research spins off start-ups that fuel the State economy.

In 2009, University of Maryland in College Park embarked on a variety of real estate and community engagement initiatives. The College Park City Community Partnership (CPCUP) is a shared nonprofit between the University, College Park, and Prince George's County that was set up to lead joint initiatives focused on housing, transportation, education, sustainability, and safety. In addition, UMD commissioned a real estate strategy that synthesized the University's Strategic Plan, the Facilities Master Plan, and CPCUP Vision. This endeavor included analyzing the internal institutional drivers that have real estate implications (housing, research, student life) and reconciling these against the market dynamics that prevailed in College Park. The strategy identified a key east-west linkage from the campus core through the Metro (rail system) to M Square (research park) hinging on Downtown as the critical juncture for redevelopment. Cumulatively, the strategies have led to the University forming a stronger working relationship in College Park, and laying the groundwork to transform the Downtown into a vibrant college town district.

Since 2012, the University of Maryland has embarked on a transformative economic development initiative that has not only attracted $\$ 1$ billion in public-private investment, but has laid the foundation for a more engaged and dynamic community in and around the campus, along with a world-class innovation ecosystem that comprises cutting edge research and new entrepreneurial activity. (University of Maryland 2016). Much of this work effort is focused on valuing real estate, assessing the market for future uses, negotiating with landowners, and coordinating amongst the University, Foundation, political leadership, and existing landowners. Together, the effort is recognized as Greater College Park. Highlights of this transformation include:

- Development of a new hotel and conference center

- Introduction of a new light rail that will connect the campus to the region

- High-tech charter school leveraging University resources

- Public-Private research and academic hub

- Redevelopment of Downtown College Park

- Attraction of start-ups and entrepreneurs to College Park

- New retail, amenities, and public spaces

- Investment in College Park City University Partnership 
Beyond the projects, the University has pioneered a collaborative process that leverages local and State government and the private sector to achieve the vision for a Greater College Park.

\section{University of Pretoria's Hatfield precinct project}

By redeploying their assets and leveraging internal demand, a number of American universities have shown how they can act as anchor institutions to transform their neighbourhoods and attract significant investment. In this regard, universities have increasingly turned to public-private partnerships and private sector engagement in the US as their local state funding has decreased over the past decade or so. The new funding approach has increased collaboration at the local level, although the nature and structure of the partnerships vary according to the particular issues that each place is facing. In this context, the different funding mechanisms and levels of philanthropy experienced by South African universities also affect what kinds of anchor strategies may be developed here. However, certain common factors apply - such as, for example, the importance of bringing the right people together and thinking about how universities can leverage their own internal demand effectively to make a difference within their local communities.

\section{University of Pretoria's Potential Role as an Anchor Institution}

Acting on concern about urban economic decay, including declining infrastructure and increasing crime, around the University of Pretoria's Hatfield campus, the vice-chancellor and Tshwane's executive mayor visited Detroit and Philadelphia in the US at the invitation of the American government to review a range of university-city building projects. After the visit, American consultants U3 Advisors, which had played an instrumental role in the West Philadelphia Initiatives, were invited to conduct a feasibility study in Hatfield in 2015.

The U3 team led focus groups of leading administrators and academics, as well as students at the University of Pretoria. It engaged community and civic leaders, including a former executive mayor of Tshwane and the local authority's city manager, foreign diplomatic missions in the area, local and national police, real estate developers and operators, representative from local schools and the business community, and members of the City Improvement District (CID) in which the university was already playing a leading role.

U3 Advisors produced a framework report identifying the university's potential as an anchor institution and the steps that needed to be taken to implement an effective anchor strategy in Hatfield (U3 Advisors 2016). In relation to the university's potential to play a place-building role similar to that adopted by anchor institutions in Pennsylvania, Detroit and College Park, the report found that the 652-hectare precinct at the University of Pretoria is comparable in size to the areas covered by Detroit Midtown Inc and the University-City District in West Philadelphia. In addition, the neighbourhood - unlike the University of Pennsylvania's, Mid-Town Detroit and the University of Maryland's - boasted all the ingredients considered crucial to changing an area's trajectory: a collaborative private real-estate market; strong urban fabric; close civicalignment; adequate precinct infrastructure; top-rated schools; and effective security (provided by national and metro police, as well as privately contracted firms hired by the university). By comparison, when the University of Pennsylvania undertook its anchor strategy, only a strong 
urban fabric and an institutional security infrastructure were in place. In Detroit and Maryland, the only inherited ingredient was adequate precinct infrastructure.

In addition, the University of Pretoria, which is academically competitive with committed staff and innovative leaders, benefits from the extent of its control over land (particularly in the street grid between the Hatfield and Hillcrest campuses); its lack of debt; its diverse student body; the support of a national mandate; and its engagement with local partners. From a physical standpoint, the compact urban fabric of the Hatfield precinct is an important asset. The street grid and relatively small blocks lend themselves to a pedestrian culture and development of groundfloor uses that promote an active street life along commercial corridors. Crucially, the Hatfield campus is also located within an active city improvement district, to which it is the largest financial contributor. The university registrar sits on the board of this legislated entity which levies local stakeholders and mainly directs these extra funds to improving the area's safety, cleanliness and beautification.

\section{The Precinct and its Assets}

The University of Pretoria had previously identified a 70-hectare precinct in the largely residential area between its Hatfield and Hillcrest campuses, and including a commercial corridor, for development. Consequently, the university has pursued a policy of purchasing housing as it becomes available in this area, and currently owns about 50 residential properties, as well as the former Nedhill Building. and the municipal property currently used by the Maritimo Football Club The U3 team took a slightly more expansive view of the neighbourhood, including blocks to the north and the south. This district, along with adjacent areas in Sunnyside, Arcadia, Menlo Park, and Groenkloof, boast important institutional assets including five highly ranked primary and secondary schools and eight hospitals.

The Hatfield City Improvement District encompasses an area that is coterminous with a large portion of the precinct proposed by U3. The CID, which promotes safety and maintenance, employs 51 "security ambassadors" and operates over 30 CCTV cameras. It is funded by a special levy paid by local property owners, with UP as its largest financial contributor. In line with South African legislation facilitating the expansion of CIDs, the Hatfield CID has proposed extending its boundaries to the eastern edge of the university's Hillcrest campus and southward.

The Hatfield precinct is linked by three Metrorail stations and a Gautrain station, as well as local bus services. In addition, the university operates a bus service connecting Hatfield with the other UP campuses in Tshwane and with areas populated by significant numbers of students, such as Sunnyside. Planned bus rapid transit routes would further connect the Hatfield campus to other areas to the east and west, although the university has some concerns about the proposed service. Meanwhile, private cars remain the main form of transport for many students and university staff and parking lots at the Hatfield and Hillcrest campuses occupy substantial space. Faculty members and students can apply for permits for reserved on-campus parking.

The university operates 28 student residences on and off the Hatfield and Hillcrest campuses, with a significant cluster at the south end of the Hillcrest campus. About 9,000 students live in these residences with four facilities dedicated to postgraduates housing approximately 1,000 of them?. An increasing number of students live in privately owned housing in the proposed 
precinct, including in communes in detached houses located in the street grid between the Hatfield and Hillcrest campuses and in dense high-rise housing developments which opened recently along one of the area's major corridors. The demand for student housing is effectively driving real-estate development in Hatfield.

\section{Place-building Challenges}

A range of neighbourhood challenges led to the University of Pretoria prioritising the improvement of the Hatfield precinct. The number of crimes against students and staff had risen at an alarming rate as the area's physical infrastructure visibly decayed. An increasing number of businesses had moved to the suburbs. The homeless population was growing. The area's public transport was inadequate and parking hard to find. As a result, an increasing number of staff and students used private cars to get as close as possible to their destinations in the precinct, leading to congestion and emptying the streets of foot traffic, which made them even less safe. The area offered students few social, sports or cultural activities, forcing them to travel further afield, which exposed them to a range of risks. In general, it was felt that Hatfield had "lost its soul". The university decided that if it did not intervene, its own sustainability - its ability to attract students and staff - would be compromised.

U3 Advisors identified a number of challenges in improving the precinct, including issues with safety and parking; a lack of recreational resources; an imbalanced real-estate market; rapid enrolment increases; unfunded university mandates; great income disparities among students; and the university's seven disparate campuses.

Crime - primarily robberies but also car hijackings - remains a problem. The response has generally been defensive. The built environment is shaped by high walls and electrified fences. In addition, many people prefer to drive and park next to their destinations rather than walk. As a result, the streets are often empty of pedestrians, even in the middle of the day. In this regard, substantial resources are dedicated to accommodating private cars on campuses.

The demand for student housing and the profits that can be made in meeting this have led to a focus on densely occupied developments built for students, which has crowded out other uses including non-student housing and commercial buildings. This real-estate monoculture has undermined prospects for greater stability and community engagement in the Hatfield area.

Meanwhile, although many more students are now enrolling at the university - a $22 \%$ increase or 10,000 additional students is forecast by 2025 (University of Pretoria 2016) - commensurate increases in funding and resources have not been forthcoming. The continuing controversy over increases in student fees at South African universities may squeeze revenue further. The University of Pretoria receives 34 percent of its funding from public subsidies, 27 percent from tuition and 39 percent from other sources. Security needs have claimed an increasing share of the budget. In addition, like its peers across South Africa, UP's mandate continues to expand at the government's behest without commensurate funds being made available.

There are also large disparities among student incomes. Although about $30 \%$ of students have enough disposable income to participate in a so-called "café culture", patronising coffee bars and restaurants, a large and growing portion percentage come from poor backgrounds and often can 
only just afford to feed themselves on a daily basis. Despite the presence of theatres and sports facilities, including for athletics, on the campus, students often cannot take advantage of these assets because of a lack of transport and the long commute. Since the closure of the former Hatfield Square development due to increased crime, deterioration and market pressures for more student housing, the need to establish a "common ground" where all members of UP's community can congregate has increased. The university has seven disparate campuses across Tshwane, which inhibits the creation of a cohesive culture for the institution.

\section{Implementing a Place-building Framework}

Although the university has successfully addressed these challenges to an extent through defensive measures, U3 Advisors asserted that a new intentional, proactive approach was required. The university was advised that it should clearly define its vision for the proposed precinct initiative based on an analysis of its developmental needs. Such clarity would enable the university's leaders to articulate and promote the university's place-building plans and support the alignment of these with the interests of the local authority and other key stakeholders as part of a long-term holistic strategy.

U3 Advisors also emphasised the importance of creating a manageable anchor strategy with measurable outcomes. In this regard, the university's real-estate holdings represent an important tool to support the cultivation of a diverse, vibrant precinct. For example, the imbalance in the local market in favour of student housing may be mitigated by providing more university-owned student housing on campus. The Hatfield CID represents a further powerful place-building tool and legal vehicle through which the university could help to improve the precinct, although it has been acknowledged that funding will need to be secured from multiple sources to pursue and implement the neighbourhood improvement strategy properly.

U3 Advisors also stressed the need to promote a robust urban-design framework. Such a framework would include:

- Diversified housing choices that allow more university staff and affiliates to live near campus;

- "Porous" campus borders which may be created by locating appropriate university services - such as UP's bookstore, galleries, and entrepreneurial initiatives including makers-places - on the edges of the campus in order to engage the surrounding community;

- Sustainable non-automobile transport systems, such as buses and shuttle services. The university should also review its parking policy. Providing underpriced, exclusive parking is exacerbating the lack of supply on the campus; and

- Civic commons. The university should foster the creation of more public spaces in the precinct where people from different backgrounds can mix "outside the fence".

Accordingly, proposed actions to develop the precinct include:

- Establishing more student housing in the southern part of the Hillcrest campus in order to mitigate the private market for such accommodation along the Burnett Street corridor;

- Expanding the university's control of housing stock in the grid between the Hatfield and Hillcrest campuses and leveraging this to encourage more young professionals and recent graduates to live here; 
- Moving parking from the Hatfield campus to undeveloped areas of the sports campus, with an increased shuttle service to provide connections;

- Preserving the low-density, high-quality residential nature of Brooklyn for housing university staff, thus encouraging recruitment and retention; and

- Continuing to pursue development of innovation centres on the Experimental Farm

\section{The Way forward}

At the behest of the Hatfield CID, the Department of Town and Regional Planning at the university, headed by a former head of city planning, developed a spatial and institutional development and management framework for the Hatfield Campus Village (Enterprises UP 2016), which was adopted in November 2016. The university prioritised its role as an anchor institution in its five year plan from 2017 to 2021 and established an Office of Special Projects with a budget and a senior university administrator which focuses on the Hatfield Campus Village project. With the support of other institutions in the city, the goal is to create greater community wealth and, thereby, contain and reverse urban decay in the district. Implementation of the framework will entail:

- Formulation of a real-estate strategy for land acquisition and development, as well as plans for affordable student housing, streetscaping, transport, maintenance, recreation, safety and disaster management;

- Capacity-building activities, including restructuring the CID as a vehicle to drive the process to improve its effectiveness, and training and orientating staff and students towards "anchor institution" thinking and planning;

- Enhanced community engagement, including plans to foster small and micro businesses that can create jobs, campaigns to counter anti-social behaviour, and outreach programmes;

- Formulation of a funding strategy, including a three-year business and income generation plan;

- Communication activities and events to win the support of local stakeholders and highlevel politicians, as well as promotional, public awareness and safety campaigns; and

- Aligning the place-building activities to ensure that they support student access, diversity, academic success, work readiness and employment.

The Hatfield Campus Village plan seeks to involve all stakeholders to achieve shared benefits, fostering urban development that is inclusive, economically and environmentally sustainable and socially responsible. The goal is further to transcend traditional boundaries that isolate higher education and research and facilitate exchange between academia and society. It is envisaged that the precinct will provide physical and social spaces that advance the socio-economic conditions of the community and at the same time support the university in achieving its strategic goals of:

- $\quad$ enhancing access and successful learning;

- $\quad$ strengthening its social responsiveness and impact on society;

- $\quad$ fostering and sustaining a diverse, inclusive and equitable university community; and

- $\quad$ enhancing institutional sustainability.

It is envisaged that the master plan for the Hatfield Campus Village can neutralise the effect of the area's negatives and leverage the university's larger impact, leading the district's 
transformation, attracting staff, students and businesses to locate in the area and fostering an open, safe, vibrant and diverse community with quality educational and recreational facilities, in particular through a culture of integration that moves beyond the gated framework. Development and implementation of the master plan will entail identifying the areas where university and local community interests intersect, giving rise to economic opportunities; demand-side interventions to buy, hire and live locally; supply-side interventions, for example, to adapt and/or build appropriate accommodation for staff and students in the area; partnering with a well-funded community organisation with a shared mission; and quick wins - the implementation of immediate opportunities that provide an incentive for future change and foster an environment for investment. The hope is that the precinct may serve as a model for urban development in other South African cities.

\section{References}

Blaik O (2016) Universities have a duty to engage with their cities. The Philadelphia Inquirer, February 2016

Midtown Detroit, Inc. 2017

Enterprises, University of Pretoria (2016) Draft Spatial and Institutional Development and Management Framework for the Hatfield Campus Village

Ford Foundation, U3 Advisors, and Lincoln Institute of Land Policy (2015) Anchors Lift All Boats: Eds and Meds Engaging with Communities. Land Lines, Winter 2015

Kromer J and Kerman L (2004) West Philadelphia Initiatives: A Case Study in Urban Redevelopment

Netter Centre (2008) Anchor Institutions Toolkit: A guide for neighbourhood revitalization. University of Pennsylvania

U3 Advisors (2016) Strategic Plan

University of Maryland (2016) Building a Greater College Park. Washington Business Journal, Winter 2016

University of Pretoria (2015) U - an engaged university. University of Pretoria Annual Review

University of Pretoria (2016) University of Pretoria Strategic Plan 2017-2021 